\title{
Association between sociodemographic, anthropometric variables, life habits and postural balance of pregnant women: a cross-sectional study
}

\author{
Vanessa Patrícia Soares de Sousa ${ }^{(1)}$, Alethéa Cury ${ }^{(1)}$, Sara Estéfani Soares de Sousa(2), Silvia Oliveira Ribeiro(1), \\ Elizabel de Souza Ramalho Viana ${ }^{(1)}$
}

\begin{abstract}
Background: Researchers have sought to evaluate the relationship between sociodemographic characteristics and life habits in maintaining the postural balance of specific populations. However, studies based on analyzing in detail the influence of these factors on this body function in pregnant women are scarce. Objective: To analyze the association between sociodemographic, obstetric, anthropometric and lifestyle characteristics and changes in postural balance in pregnant women. Method: Cross-sectional study carried out from February 2012 to March 2015 at the Federal University of Rio Grande do Norte (UFRN). The sample consisted of 263 pregnant women. Balance Master System ${ }^{\circledR}$ (NeuroCom, Clackamas, USA) was used for balance evaluation. The bivariate analysis was performed by applying the chi-square test $\left(x^{2}\right)$. Results: The results suggest that the absence of alterations in the variables related to static postural balance is associated with higher levels of education, higher income and age over 29 years $\left(x^{2}=4.73, P=0.03\right)$. In addition, during the evaluation of the dynamic balance, it was verified that the absence of abnormalities is related to income higher than 4 minimum wages $\left(x^{2}=3.98, P=0.04\right)$, while changes in lateral displacement were associated with lower body weight (up to $\left.68 \mathrm{~kg}\right)\left(x^{2}=12.2, P=0.03\right)$. Conclusion: There is an association between sociodemographic characteristics, life habits and changes in the postural balance of pregnant women.
\end{abstract}

Keywords: Income Age; Gestational Age; Pregnancy; Postural Equilibrium.

\section{INTRODUCTION}

The gestational period is characterized by several biomechanical changes, among them, those related to postural balance ${ }^{(1)}$. The modification of this function has a multifactorial origin, namely: 1 - change in body mass distribution, mainly in the abdomen region, 2 - anteroposterior transfer of the center of gravity, requiring an effective response of the ankle joint ${ }^{(2)}$ and 3 - possible changes in the size of the support base and alteration of the sensory systems (visual, somatosensory and vestibular) ${ }^{(3)}$.

Currently, researchers have also sought to evaluate the relationship between socio-demographic characteristics and life habits of specific populations, regarding the maintenance of postural balance $e^{(4)}$. Studies with groups of obese patients ${ }^{(5)}$ and young adults( ${ }^{(6)}$ analyzed the relationship between these variables. In this sense, the physiological and biomechanical justifications which support the static and dynamic balance changes during gestation are well established in the literature. However there are few studies that analyze in detail the influence of sociodemographic, obstetric, anthropometric and lifestyle characteristics on this body function in pregnant women. The study of this theme is justified by the fact of postural balance alterations increase the risk of falls in this population $^{(3)}$ and represent $17-39 \%$ of maternal traumas ${ }^{(7)}$, accounting for $3-7 \%$ of fetal deaths ${ }^{(7)}$. The aim of this study was to analyze the association between sociodemographic, obstetric, anthropometric and lifestyle characteristics with changes in postural balance in pregnant women.

\section{METHODS}

This cross-sectional study was conducted from February 2012 to March 2015, at the Physiotherapy Department of the Federal University of Rio Grande do Norte (UFRN). The voluntary pregnant women were enrolled in the Preparatory Course for Gestation, Childbirth and Postpartum (PCGCP). The sampling process was non-probabilistic. The final sample consisted of 263 pregnant women, who followed such inclusion criteria, present a low-risk pregnancy, sign the free and informed consent form, absence of twin pregnancy, 
musculoskeletal or neurological abnormalities that affect postural balance and use of medication that interferes with postural balance. After the tests were presented, if the volunteer refused to perform them, she would be excluded from the research. All the participants signed the informed consent term. This study was approved by the Committee of Ethics in Research with Human Beings of UFRN, under the number of protocol 719.939 and CAAE 30403414.8.0000.5537.

\section{Data Acquisition and evaluation procedures}

Sociodemographic, clinical, obstetrical and lifestyles information were collected through an instrument developed by the responsible researchers. Balance Master Balance System (NeuroCom, Clackamas, USA) was used to assess the balance. This equipment is a system that uses the force platform, with four transducers, that measure the vertical reaction forces exerted by the feet of the individual. From the pressure center (COP) data, an estimate of the center of gravity (CG) is calculated, based on the height of the subject. Static and dynamic balance analysis was performed using the Modified Clinical Test of Sensory Interaction on Balance (mCTSIB) and Rhythmic Weight Shift Test (RWS) tests, respectively. During the execution of the MCTSIB test, the participants had the velocity of postural oscillation evaluated in three different situations, obtaining three measures for each test condition: (1) firm surface and open eyes (VFOA), (2) firm surface and closed eyes (VFOF) and (3) unstable and closed eyes (VIOF). Each test attempt lasted 10 seconds (time set by the device). The mean oscillation velocity of the three trials, in each condition, was considered for analysis. In all situations, the volunteer was instructed to keep the upper limbs close and along the body.

The RWS resembles virtual reality games, in which the subject is represented on the computer screen by an Avatar video game. Before starting the test, the participants were instructed to remain with their arms along the body, keeping the trunk erect and performing lateral-lateral and anteroposterior weight displacements, in three distinct speeds: low, medium and high, causing the Avatar remained between two parallel bars displayed on the computer screen during the test. Accordingly, the following variables related to dynamic postural balance were selected: velocity of oscillation during lateral-displacement (VOLL) and directional in the lateral-lateral (CDLL). This variables related to the movement of getting up from the sitting position were obtained through the Sit to Stand (STS) test, also performed through the Balance Master $^{\circledR}$. To perform the test, the volunteers were instructed to sit on a bench, maintaining 90 o of flexion of hips and knees, with upper limbs (UL) positioned along the body. When viewing the "Go" command on the computer screen, the volunteers should stand up by exerting only force on the lower limbs without the aid of the UL. Afterwards, they should remain standing, for approximately 10 seconds. This procedure was performed three times in order to calculate the mean of the data in the three trials. By means of the test, the following variables were selected: weight transfer (TT), which translates as the time, in seconds, necessary to voluntarily change the COP previously, starting from the sitting position to orthostatism; and oscillation velocity (OV), which records the maintenance control of this inside the support base, during the climb phase, and 5 seconds after ${ }^{(1,2,8)}$.

\section{STATISTICAL ANALYSIS}

The data analysis was performed through the Statistical Package for Social Sciences (SPSS - 20.0). The Shapiro Wilk test was used to verify the quantitative variables normality. The sociodemographic, anthropometric, obstetric and life habits characteristics were presented as mean, standard deviation and absolute and relative frequencies. To examine the existence of an association between the variables of interest, the bivariate analysis was conducted using the Chi-square test $\left(x^{2}\right)$. The independent variables were divided into four groups: sociodemographic (age, schooling and income), obstetric (gestational trimester and number of pregnancies), anthropometric and life habits (weight, height and physical activity practice). The dependent variables were those related to static postural balance (VFOA, VFOF and VIOF), dynamic (VOLL and CDLL) and the movement of getting up from the sitting position (TT and VO). All variables were transformed into dichotomies for that reason they could be included in the $2 \times 2$ contingency table, and then the selected test was applied. A level of significance of $P<0.05$ was considered statistically significant, thus establishing an association between the variables. The power of this study was verified using $\mathrm{G} *$ Power software (GPower, Germany, version 3.1.9.2), considering the effect size $0.5, \beta / \alpha$ ratio of 1 and sample of 263 volunteers. The power of the study was $99 \%$.

\section{RESULTS}

The sociodemographic, obstetric, anthropometric and life habits of the sample $(n=263)$ showed the average chronological and gestational age were, respectively, $29.7 \pm 4.6$ years and $23.0 \pm 6.43$ weeks. The majority of the sample had higher education (92.4\%) and family income greater than 4 Brazilian minimum wages (66.2\%). In addition, $64.6 \%$ of the volunteers did not engage in physical activity and had a mean body weight of $67.7 \pm 10.9 \mathrm{~kg}$. The other variables of characterization of the sample are presented in Table 1.

When analyzing the relationship between the independent variables and the behavior of the static balance, a significant association between schooling and oscillation velocity was observed on firm surface under open-sensory conditions $\left(x^{2}=5.51, P=0.01\right)$ and closed $\left(x^{2}=7.83, P=0.005\right)$. Furthermore, the OV, on unstable surfaces and with eyes closed, was significantly associated with age $\left(x^{2}=4.73\right.$, $P=0.03)$, schooling $\left(x^{2}=4.93, P=0.002\right)$, and income 
Table 1. Sociodemographic, obstetric, anthropometric and lifestyle characteristics.

\begin{tabular}{|c|c|}
\hline Variables & $n=263$ \\
\hline \multicolumn{2}{|l|}{ Sociodemographic variables } \\
\hline Age & $29.7 \pm 4.6$ \\
\hline \multicolumn{2}{|l|}{ Education } \\
\hline High school & $7.2 \%$ \\
\hline Higher education & $92.4 \%$ \\
\hline Did not answer & $0.4 \%$ \\
\hline \multicolumn{2}{|l|}{ Income } \\
\hline 1 to 4 salaries & $25.9 \%$ \\
\hline$>4$ salaries & $66.2 \%$ \\
\hline Did not answer & $8 \%$ \\
\hline \multicolumn{2}{|l|}{ Conjugal situation } \\
\hline Married & $73 \%$ \\
\hline Stable union & $24.3 \%$ \\
\hline Single & $2.7 \%$ \\
\hline \multicolumn{2}{|l|}{ Obstetric Variables } \\
\hline Gestational age & $23.0 \pm 6.43$ \\
\hline Number of pregnancies & $1.26 \pm 0.69$ \\
\hline \multicolumn{2}{|c|}{ Anthropometric Variables and Life Habits } \\
\hline Weight & $67.7 \pm 10.9$ \\
\hline Height & $1.62 \pm 0.06$ \\
\hline \multicolumn{2}{|l|}{ Physical activity practice } \\
\hline No & $64.6 \%$ \\
\hline Yes & $34.6 \%$ \\
\hline Did not answer & $0.8 \%$ \\
\hline
\end{tabular}

Note: The values of the quantitative variables are presented in mean and standard deviation. Categorical variables are displayed by relative frequencies.

$\left(x^{2}=12.2, P=0.001\right)$ (Table 2$)$. The velocity of oscillation during the execution of the lateral-lateral movement and the directional control, referring to dynamic postural balance, were significantly associated, respectively, to income $\left(x^{2}=3.98, P=0.04\right)$ and to weight $\left(x^{2}=12.2, P=0.03\right)$ of the sample (Table 3 ). Significant associations between weight and OV $\left(x^{2}=5.53, P=0.001\right)$, as well as between weight and transfer time, were observed during the standing up activity. $\left.x^{2}=8.43, P=0.04\right)$. No other associations were found (Table 4).

\section{DISCUSSION}

This study main results are high socioeconomic level (schooling and income), as well as age above 29 years are associated to the absence of static balance alteration; income above 4 minimum wages and weight up to $68 \mathrm{~kg}$ are associated with the absence of dynamic equilibrium change and, in relation to the upward movement, the variable weight of up to $68 \mathrm{~kg}$ is associated with the absence of changes in oscillation speed.
The volunteers above 29 years of age with higher education and monthly income greater than four minimum wages did not present alterations in the variables related to the maintenance of the static postural balance. And they did not present altered balance. This finding is corroborated by the results obtained by Faraldo-Garcia et al. that evaluated the postural balance of healthy subjects, comparing 7 different age groups ${ }^{(9)}$. Contrary to expectations, there was no worsening of stability, related to advancing age. This seems to be justified by the fact that the deterioration of sensory systems, expected over the years, is compensated by the body's ability to adapt to specific sensory situations $^{(9)}$. The results of the present study are refuted by other data documented in the literature which shows the increasing age as a factor that leads to the deterioration of systems related to the balance maintenance ${ }^{(10,11)}$. Jalali et al. evaluating the balance of 448 elderly people, found that those older than 75 years presented worse performance in the balance tests, when compared to those less than 75 years old. For these authors advanced age is a risk factor for changes in balance. With regard to the population of pregnant women, there are no studies that specifically evaluate the relationship between balance and chronological age ${ }^{(12)}$.

But on the other hand, the finding of association between high socioeconomic levels (income and schooling) and absence of static equilibrium change are corroborated by Stevens et al. These authors, through conducting cross-sectional studies, observed that lower socioeconomic status was associated with poor postural balance control ${ }^{(13)}$. However, it should be noted that these studies did not assess populations of pregnant women. It is considered pregnant women with higher income and education have easier access to health professionals specialized in obstetrics, health guidance groups and the most diverse information, transmitted by the media. This may exert an attenuating effect on the changes arising from the pregnancy period, including those related to postural balance.

The findings of the study on the obstetric variables had no association with the balance of pregnant women. The association absence between gestational trimester and postural balance, found in this study, is corroborated by Aguiar et al. These authors conducted a survey with 90 pregnant women, between 18 and 35 years old, and found very weak correlations and no statistical significance regarding the center of gravity and the gestational trimesters. They detected an increase in static oscillation, both in the anteroposterior and laterolateral directions, as the pregnancy progresses. But, they did not observe statistically significant differences in the oscillation of pregnant women in the third trimester when compared to those in the first and second trimester of pregnancy ${ }^{(14)}$.

In contrast, the results obtained by McCrory and colleagues $^{(15)}$ refute the findings of our study. For them the pregnant women, in the third trimester, presented a lower $\mathrm{OV}$, when compared to the second trimester and in the 
Table 2. Association of sociodemographic, obstetric, anthropometric and lifestyle variables with changes in static postural balance, considering the measurements obtained through the ModifiedClinical Test of Sensory Interactionon Balance (mCTSIB).

\begin{tabular}{|c|c|c|c|c|c|c|c|c|c|c|c|c|}
\hline \multirow{3}{*}{ Variables } & \multirow{2}{*}{\multicolumn{2}{|c|}{$\begin{array}{c}\begin{array}{c}\text { Change of } \\
\text { Postural } \\
\text { Equilibrium }\end{array} \\
\text { VOFOA( } \% / s)\end{array}$}} & \multirow{3}{*}{$x^{2}$} & \multirow{3}{*}{$P$} & \multirow{2}{*}{\multicolumn{2}{|c|}{$\begin{array}{c}\begin{array}{c}\text { Change of } \\
\text { Postural } \\
\text { Equilibrium }\end{array} \\
\text { VOFOF }(\% / s)\end{array}$}} & \multirow{3}{*}{$x^{2}$} & \multirow{3}{*}{$P$} & \multirow{2}{*}{\multicolumn{2}{|c|}{$\begin{array}{c}\begin{array}{c}\text { Change of } \\
\text { Postural } \\
\text { Equilibrium }\end{array} \\
\text { VOIOF }(\% / s)\end{array}$}} & \multirow{3}{*}{$x^{2}$} & \multirow{3}{*}{$P$} \\
\hline & & & & & & & & & & & & \\
\hline & no & yes & & & no & yes & & & no & yes & & \\
\hline \multicolumn{13}{|c|}{ Sociodemographic variables } \\
\hline \multicolumn{13}{|l|}{ Age } \\
\hline Up to 29 years & 92 & 12 & \multirow{2}{*}{0.53} & \multirow[t]{2}{*}{0.46} & 96 & 8 & \multirow[t]{2}{*}{3.26} & \multirow[t]{2}{*}{0.07} & 100 & 4 & \multirow[t]{2}{*}{4.73} & \multirow[t]{2}{*}{0.03} \\
\hline$>29$ years & 103 & 18 & & & 118 & 3 & & & 121 & 0 & & \\
\hline \multicolumn{13}{|l|}{ Education } \\
\hline High school & 10 & 5 & \multirow[t]{2}{*}{5.51} & \multirow[t]{2}{*}{0.01} & 12 & 3 & \multirow[t]{2}{*}{7.83} & \multirow[t]{2}{*}{0.005} & 13 & 2 & \multirow[t]{2}{*}{12.2} & \multirow[t]{2}{*}{0.001} \\
\hline Higher education & 184 & 25 & & & 201 & 8 & & & 207 & 2 & & \\
\hline \multicolumn{13}{|l|}{ Income } \\
\hline 1 to 4 salaries & 50 & 5 & \multirow[t]{2}{*}{1.00} & \multirow[t]{2}{*}{0.31} & 50 & 5 & 2.15 & 0.14 & 52 & 3 & 4.94 & 0.002 \\
\hline$>4$ salaries & 131 & 22 & & & 147 & 6 & & & 152 & 1 & & \\
\hline Obstetric Variables & & & & & & & & & & & & \\
\hline Gestational age & & & & & & & & & & & & \\
\hline Second trimester & 93 & 17 & 0.83 & 0.36 & 104 & 6 & 0.14 & 0.70 & 109 & 1 & 0.93 & 0.33 \\
\hline Third quarter & 102 & 13 & & & 110 & 5 & & & 112 & 3 & & \\
\hline Number of pregnanci & & & & & & & & & & & & \\
\hline Up to 2 pregnancies & 187 & 30 & 1.27 & 0.25 & 206 & 11 & 0.42 & 0.51 & 213 & 4 & 0.14 & 0.69 \\
\hline$>2$ pregnancies & 8 & 0 & & & 8 & 0 & & & 8 & 0 & & \\
\hline Anthropometric Vari & es and & Habits & & & & & & & & & & \\
\hline Weight & & & & & & & & & & & & \\
\hline Up to $68 \mathrm{~kg}$ & 108 & 19 & 0.48 & 0.48 & 120 & 7 & 0.18 & 0.67 & 126 & 1 & 1.75 & 1.18 \\
\hline$>68 \mathrm{~kg}$ & 88 & 11 & & & 90 & 4 & & & 91 & 3 & & \\
\hline Height & & & & & & & & & & & & \\
\hline Up to $1.62 \mathrm{~m}$ & 99 & 16 & 0.65 & 0.81 & 107 & 8 & 2.11 & 0.14 & 112 & 3 & 0.99 & 0.33 \\
\hline$>1.62 \mathrm{~m}$ & 95 & 14 & & & 106 & 3 & & & 108 & 1 & & \\
\hline Physical activity pract & & & & & & & & & & & & \\
\hline No & 120 & 24 & 3.60 & 0.05 & 135 & 9 & 1.50 & 0.22 & 142 & 2 & 0.37 & 0.53 \\
\hline Yes & 73 & 6 & & & 77 & 2 & & & 77 & 2 & & \\
\hline
\end{tabular}

Note: VOFOA, oscillation speed on firm surface and with eyes open; VOFOF, steady surface oscillation velocity with eyes closed; VOIOF, oscillation velocity on unstable surfaces and with eyes closed. The values are presented in absolute frequencies and concern the analysis of postural balance of 225 volunteers. Thirty-eight pregnant women did not perform the test.

control group. Similarly, another study evaluating the static equilibrium of pregnant women found the rate of oscillation increased with the progress of the gestational trimesters ${ }^{(1)}$. It is known that the requirements of the systems involved in maintaining postural balance are higher in pregnant women when compared to non-pregnant women ${ }^{(7)}$.

This is mainly due to the biomechanical changes that the body undergoes during the pregnancy period. Some researchers hypothesize the maintenance of postural stability in this population is more related to hormonal, ligamentous and joint changes than the increase of the abdomen and weight gain (2). The difference between the results of this study and those found in the literature can be justified by the individuality of adaptation of each pregnant woman to the changes arising from the pregnancy period. Regarding the association between number of pregnancies and postural balance, Ersal, McCrory and, Sienko reported that hormone-mediated balance changes during gestation may also result from increased body mass and decreased nerve conduction and neuromuscular coordination ${ }^{(2)}$. Considering such changes may be cumulative, according to the number of 
Table 3. Association of sociodemographic, obstetric, anthropometric and life-style variables with changes in dynamic postural balance, considering the RhytmicWheight Shift (RWS) test.

\begin{tabular}{|c|c|c|c|c|c|c|c|c|}
\hline \multirow{3}{*}{ Variables } & \multirow{2}{*}{\multicolumn{2}{|c|}{$\begin{array}{c}\begin{array}{c}\text { Change of } \\
\text { Postural Equilibrium }\end{array} \\
\text { VOLL }(\mathrm{em} \% \mathrm{~s})\end{array}$}} & \multirow{3}{*}{$x^{2}$} & \multirow{3}{*}{$P$} & \multirow{2}{*}{\multicolumn{2}{|c|}{$\begin{array}{c}\begin{array}{c}\text { Change of } \\
\text { Postural Equilibrium }\end{array} \\
\text { CDLL (em \%) }\end{array}$}} & \multirow{3}{*}{$x^{2}$} & \multirow{3}{*}{$P$} \\
\hline & & & & & & & & \\
\hline & no & yes & & & no & yes & & \\
\hline \multicolumn{9}{|c|}{ Sociodemographic variables } \\
\hline \multicolumn{9}{|l|}{ Age } \\
\hline Up to 29 years & 77 & 25 & \multirow{2}{*}{0.38} & \multirow[t]{2}{*}{0.53} & 26 & 76 & \multirow[t]{2}{*}{0.26} & \multirow[t]{2}{*}{0.60} \\
\hline$>29$ years & 94 & 25 & & & 34 & 85 & & \\
\hline \multicolumn{9}{|l|}{ Education } \\
\hline High school & 9 & 6 & \multirow[t]{2}{*}{2.73} & \multirow[t]{2}{*}{0.09} & 3 & 12 & \multirow[t]{2}{*}{0.42} & \multirow[t]{2}{*}{0.51} \\
\hline Higher education & 161 & 44 & & & 57 & 148 & & \\
\hline \multicolumn{9}{|l|}{ Income } \\
\hline 1 to 4 salaries & 37 & 18 & \multirow[t]{2}{*}{3.98} & \multirow[t]{2}{*}{0.04} & 14 & 40 & \multirow[t]{2}{*}{2.15} & \multirow[t]{2}{*}{0.14} \\
\hline$>4$ salaries & 120 & 29 & & & 40 & 109 & & \\
\hline \multicolumn{9}{|l|}{ Obstetric Variables } \\
\hline \multicolumn{9}{|l|}{ Gestational age } \\
\hline Second trimester & 112 & 38 & \multirow[t]{2}{*}{1.95} & \multirow[t]{2}{*}{0.16} & 42 & 108 & \multirow[t]{2}{*}{0.17} & \multirow[t]{2}{*}{0.67} \\
\hline Third quarter & 59 & 12 & & & 18 & 53 & & \\
\hline \multicolumn{9}{|l|}{ Number of pregnancies } \\
\hline Up to 2 pregnancies & 165 & 47 & 0.61 & 0.43 & 57 & 155 & 0.42 & 0.51 \\
\hline$>2$ pregnancies & 6 & 3 & & & 3 & 6 & & \\
\hline Anthropometric Variak & Habits & & & & & & & \\
\hline Weight & & & & & & & & \\
\hline Up to $68 \mathrm{~kg}$ & 96 & 28 & 0.22 & 0.88 & 27 & 97 & 4.50 & 0.03 \\
\hline$>68 \mathrm{~kg}$ & 72 & 20 & & & 32 & 60 & & \\
\hline Height & & & & & & & & \\
\hline Up to $1.62 \mathrm{~m}$ & 84 & 29 & 1.91 & 0.16 & 28 & 85 & 0.80 & 0.37 \\
\hline$>1.62 \mathrm{~m}$ & 87 & 19 & & & 32 & 74 & & \\
\hline Physical activity practic & & & & & & & & \\
\hline No & 106 & 36 & 1.45 & 0.22 & 30 & 103 & 0.45 & 0.22 \\
\hline Yes & 63 & 14 & & & 20 & 57 & & \\
\hline
\end{tabular}

Note: VOLL, oscillation speed during the lateral-lateral displacement; CDLL, directional control during the lateral-lateral displacement. The values are presented in absolute frequencies and concern the analysis of the postural balance of 219 volunteers. Forty-four pregnant women did not perform the test.

pregnancies in which the woman presented hypothesized, in that study, parity would be associated with changes in balance.

This may be justified by the discrepancy in the number of volunteers between the groups considered (up to two pregnancies and $>2$ pregnancies). Most of the volunteers were primi-gravidae and this fact may have influenced the absence of significant association between the selected variables. However, studies need to be conducted to corroborate or refute this relationship.

Anthropometric variables can influence motor strategies related to the maintenance of postural balance ${ }^{(6)}$. Although weight and body mass index are directly related to this body function, studies which are available in the literature have evaluated this relationship in specific groups such as obes $^{(5)}$, elderly ${ }^{(10)}$ and athletes. However, to date, no studies were found to assess the influence of anthropometric variables on the postural balance of pregnant women. We observed that pregnant women, weighing up to $68 \mathrm{~kg}$, did not present alterations in the variables related to dynamic postural balance and to those inherent to sit-up activity. This finding is supported by similar work performed with obese people, showing that there is a direct relationship between weight gain and decrease in postural stability ${ }^{(5)}$. The biomechanical alterations, due to the increase in body weight and growth of 
Table 4. Association of sociodemographic, obstetric, anthropometric and life-style variables with changes in dynamic postural balance, considering the measurements obtained through the Sit to Stand test (STS).

\begin{tabular}{|c|c|c|c|c|c|c|c|c|}
\hline \multirow{3}{*}{ Variables } & \multirow{2}{*}{\multicolumn{2}{|c|}{$\begin{array}{c}\begin{array}{c}\text { Change of } \\
\text { Postural Equilibrium }\end{array} \\
\text { vo }(\% / \mathrm{s})\end{array}$}} & \multirow{3}{*}{$x^{2}$} & \multirow{3}{*}{$P$} & \multirow{2}{*}{\multicolumn{2}{|c|}{$\begin{array}{c}\begin{array}{c}\text { Change of } \\
\text { Postural Equilibrium }\end{array} \\
\mathrm{TT}(\mathrm{s})\end{array}$}} & \multirow{3}{*}{$x^{2}$} & \multirow{3}{*}{$P$} \\
\hline & & & & & & & & \\
\hline & no & yes & & & no & yes & & \\
\hline \multicolumn{9}{|l|}{ Sociodemographic variables } \\
\hline \multicolumn{9}{|l|}{ Age } \\
\hline Up to 29 years & 100 & 3 & \multirow{2}{*}{1.34} & \multirow[t]{2}{*}{0.24} & 83 & 18 & \multirow[t]{2}{*}{0.63} & \multirow[t]{2}{*}{0.42} \\
\hline$>29$ years & 118 & 1 & & & 105 & 17 & & \\
\hline \multicolumn{9}{|l|}{ Education } \\
\hline High school & 15 & 0 & \multirow[t]{2}{*}{0.29} & \multirow[t]{2}{*}{0.58} & 13 & 0 & \multirow[t]{2}{*}{2.58} & \multirow[t]{2}{*}{0.10} \\
\hline Higher education & 202 & 4 & & & 174 & 35 & & \\
\hline \multicolumn{9}{|l|}{ Income } \\
\hline 1 to 4 salaries & 56 & 0 & \multirow[t]{2}{*}{1.53} & \multirow[t]{2}{*}{0.21} & 46 & 9 & \multirow[t]{2}{*}{0.001} & \multirow[t]{2}{*}{0.98} \\
\hline$>4$ salaries & 145 & 4 & & & 127 & 25 & & \\
\hline \multicolumn{9}{|l|}{ Obstetric Variables } \\
\hline \multicolumn{9}{|l|}{ Gestational age } \\
\hline Second trimester & 149 & 1 & \multirow[t]{2}{*}{3.36} & \multirow[t]{2}{*}{0.06} & 126 & 33 & \multirow[t]{2}{*}{0.90} & \multirow[t]{2}{*}{0.34} \\
\hline Third quarter & 69 & 3 & & & 62 & 2 & & \\
\hline \multicolumn{9}{|l|}{ Number of pregnancies } \\
\hline Up to 2 pregnancies & 209 & 4 & 0.17 & 0.68 & 183 & 33 & 0.90 & 0.34 \\
\hline$>2$ pregnancies & 9 & 0 & & & 5 & 2 & & \\
\hline Anthropometric Variables a & & & & & & & & \\
\hline Weight & & & & & & & & \\
\hline Up to $68 \mathrm{~kg}$ & 125 & 0 & 5.53 & 0.01 & 112 & 11 & 8.43 & 0.04 \\
\hline$>68 \mathrm{~kg}$ & 88 & 4 & & & 73 & 22 & & \\
\hline Height & & & & & & & & \\
\hline Up to $1.62 \mathrm{~m}$ & 113 & 1 & 1.17 & 0.27 & 94 & 19 & 0.001 & 0.97 \\
\hline$>1.62 \mathrm{~m}$ & 103 & 3 & & & 93 & 14 & & \\
\hline Physical activity practice & & & & & & & & \\
\hline No & 139 & 2 & 0.33 & 0.56 & 126 & 19 & 1.11 & 0.29 \\
\hline Yes & 78 & 2 & & & 62 & 14 & & \\
\hline
\end{tabular}

Note: VO, oscillation speed; TT, transfer time from the center of gravity in the sitting to standing position. The values are presented in absolute frequencies and concern the analysis of the postural balance of 221 volunteers. Forty-two pregnant women did not perform the test.

the gravid uterus, lead to the change in the center of gravity and as a result greater postural instability ${ }^{(16)}$.

When analyzing, specifically, the variables related to sit-up, it was demonstrated that this activity presented the greatest limitations, according to the reports of pregnant women ${ }^{(17)}$. During pregnancy, it becomes progressively more difficult to get up, which is strongly influenced by weight gain, especially at the end of gestation ${ }^{(18)}$. From the weight gain, the hip, knee and ankle joints are affected through gravitational and acceleration factors. The movements begin to be adapted and the inter segmental moments modified to fit the form and inertia of the body inferior region, generating adjustments in both posture and gait ${ }^{(19)}$. Besides, Hue et al. suggest that increased body weight leads to an attenuation of cutaneous afferents by mechanoreceptors. This result is an increase in the reaction force to the ground and, consequently, greater body instabilities ${ }^{(20)}$. Pregnant women weighing up to $68 \mathrm{~kg}$ may present a lower overload of the postural balance control mechanisms and, therefore, present greater body stability when performing sit-up.

Additionally, it was observed that the practice of physical activity, related to the habits of life, was not associated with alterations of the balance. This finding seems to be justified by the variability of type and frequency of physical activity 
practiced by the pregnant women of this research. In an evaluative interview, conducted with the volunteers of this study, it was observed that an insufficient weekly practice ( 2 times a week) and varied activities (Pilates, aqua-gymnastics, walking) may have interfered with the findings of this research. This is corroborated by the recommendation of the American College of Obstetricians and Gynecologists that during pregnancy women should practice 30 minutes of moderate activity on the greatest number of days per week ${ }^{(21)}$.

\section{CONCLUSION}

As a final point, this study suggests the alteration absence in variables related to static postural balance is associated with high levels of schooling, income and ages greater than 29 years. Through the dynamic balance evaluation was verified the absence of abnormalities in the VOLL is related to the income greater than 4 wages, whereas the changes in the CDLL were associated with lower values of body weight (up to $68 \mathrm{~kg}$ ), and the alteration absence in OV and TT during the movement execution of rising from the seated position is associated with a lower body weight. This is the first Brazilian study to analyze the association between sociodemographic, obstetric, anthropometric variables, life habits and the postural balance of pregnant women. There is a need for more discussion amongst researchers about this theme, considering this specific population. The relevance of such investigations is both intrinsic factors (obstetric variables and age, for example) and extrinsic factors (income, schooling, among others) may interfere with the onset of altered postural balance in pregnant women. This knowledge may guide specific clinical decision-making by midwifery professionals.

\section{AUTHORS CONTRIBUTIONS}

VPSS: The article idea conception, introduction writing, methods, results, discussion, conclusion and analysis of the data; AC: collaboration in writing the introduction and discussion; SESS: collaboration in writing the discussion; SOR: collaboration in writing the discussion; ESRV: guidance on the writing of the manuscript and final correction.

\section{CONFLICTS OF INTEREST}

None

\section{AUTHOR DETAILS}

(2) Departamento de Nutrição, Universidade Federal do Rio Grande do Norte, Natal, Rio Grande do Norte, Brazil.

\section{REFERENCES}

1. Butler EE, Colón I, Druzin ML, Rose J. Postural equilibrium during pregnancy: decreased stability with an increased reliance on visual cues. Rev. J Obstet Gynecol. 2006;195(4):1104-8.
2. Ersal T, McCrory JL, Sienko KH. Theoretical and experimental indicators of falls during pregnancy as assessed by postural perturbations. Gait Posture. 2014;39(1):218-23.

3. Mann L, Kleinpaul JF, Teixeira CS, Mota CB. Influência dos sistemas sensoriais na manutenção do equilíbrio em gestantes. Fisioter em Mov. 2011;24(2):315-25.

4. Rodríguez López S, Nilsson C, Lund R, Montero P, Fernández-Ballesteros $\mathrm{R}$, Avlund K. Educational differences in mobility: the contribution of physical workload, obesity, smoking and chronic conditions. J Epidemiol Community Heal. 2006;61(2):139-45.

5. Yi LC, Neves ALS, Areia M, Neves JMO, de Souza TP, Caranti DA. Influênncia do índice de massa corporal no equilíbrio e na configuração plantar em obesos adultos. Rev Bras Med do Esporte. 2014;20(1):70-3.

6. Greve JMDA, Cuğ M, Dülgeroǧlu D, Brech GC, Alonso AC. Relationship between anthropometric factors, gender, and balance under unstable conditions in young adults. Biomed Res Int. 2013. http://dx.doi. org/10.1155/2013/850424

7. McCrory JL, Chambers AJ, Daftary A, Redfern MS. Dynamic postural stability in pregnant fallers and non-fallers. BJOG An Int J Obstet Gynaecol. 2010;117(8):954-62.

8. Sit-to-Stand: Functional Limitation Assessments: NeuroCom - Products: Protocols [acess in: $2016 \mathrm{Jan}$ ]. Avaliable in: www.neurocom.com.

9. Faraldo-García A, Santos-Pérez S, Crujeiras R, Soto-Varela A. Postural changes associated with ageing on the sensory organization test and the limits of stability in healthy subjects. Auris Nasus Larynx. 2016;43(2):14954.

10. Alexander NB. Postural Control in Older Adults. J Am Geriatr Soc .1994;42(1):93-108.

11. O'Hagan C, O'Connell B. The relationship between patient blood pathology values and patient falls in an acute-care setting: a retrospective analysis. Int J Nurs Pract. 2005; 11(4):161-8.

12. Jalali MM, Gerami H, Heidarzadeh A, Soleimani R. Balance performance in older adults and its relationship with falling. Aging Clin Exp Res . 2015;27(3):287-96.

13. Stevens KN, Lang IA, Guralnik JM, Melzer D. Epidemiology of balance and dizziness in a national population: findings from the English Longitudinal Study of Ageing. Age Ageing. 2008;37(3):300-5.

14. Aguiar L, Santos-Rocha R, Vieira F, Branco M, Andrade C, Veloso A. Comparison between overweight due to pregnancy and due to added weight to simulate body mass distribution in pregnancy. Gait Posture 2015;42(4):511-7.

15. McCrory JL, Chambers A, Daftary A, Redfern MS. Dynamic postural stability during advancing pregnancy. J Biomech. 2010;43(12):2434-9.

16. De Conti MHS, Calderon I de MP, Rudge MVC. Desconfortos músculoesqueléticos na gestação: uma visão obstétrica e fisioterápica. Femina. 2003;31(6):531-5.

17. Lou S, Chou Y, Chou P, Lin C, Chen U. Sit-to-stand at different periods of pregnancy. Clin Biomech. 2001;16:194-8.

18. Nagai $M$, Isida M, Saitoh J, Hirata $Y$, Natori H, Wada M. Characteristics of the control of standing posture during pregnancy. Neurosci Lett. 2009;462(2):130-4.

19. Błaszczyk JW, Opala-Berdzik A, Plewa M. Adaptive changes in spatiotemporal gait characteristics in women during pregnancy. Gait Posture. 2015;43:160-4.

20. Hue O, Simoneau M, Marcotte J, Berrigan F, Doré J, Marceau P, et al. Body weight is a strong predictor of postural stability. Gait Posture. 2007;26(1):32-8.

21. Harrod CS, Chasan-Taber L, Reynolds RM, Fingerlin TE, Glueck DH, Brinton JT, et al. Physical activity in pregnancy and neonatal body composition: the Healthy Start study. Obstet Gynecol. 2014;124:257-64. 